\title{
Optical Imaging of Pancreatic Innervation
}

\author{
Madina Makhmutova * and Alejandro Caicedo * \\ Division of Endocrinology, Diabetes and Metabolism, Department of Medicine, University of Miami Miller School of Medicine, \\ Miami, FL, United States
}

At the time of Ivan Pavlov, pancreatic innervation was studied by looking at pancreas secretions in response to electrical stimulation of nerves. Nowadays we have ways to visualize neuronal activity in real time thanks to advances in fluorescent reporters and imaging techniques. We also have very precise optogenetic and pharmacogenetic approaches that allow neuronal manipulations in a very specific manner. These technological advances have been extensively employed for studying the central nervous system and are just beginning to be incorporated for studying visceral

OPEN ACCESS

Edited by:

Vincent Poitout,

Université de Montréal, Canada

Reviewed by:

Valentine S. Moulle,

INRAE UMR PhAN 1280, France

Christophe Magnan,

Université Paris Diderot, France

Gabriela Da Silva Xavier,

University of Birmingham,

United Kingdom

${ }^{*}$ Correspondence:

Madina Makhmutova

m.makhmutova@med.miami.edu

Alejandro Caicedo

acaicedo@med.miami.edu

Specialty section:

This article was submitted to Diabetes: Molecular Mechanisms,

a section of the journal

Frontiers in Endocrinology

Received: 02 February 2021

Accepted: 08 April 2021

Published: 27 April 2021

Citation:

Makhmutova M and

Caicedo A (2021) Optical Imaging

of Pancreatic Innervation.

Front. Endocrinol. 12:663022.

doi: 10.3389/fendo.2021.663022 innervation. Pancreatic innervation is complex, and the role it plays in physiology and pathophysiology of the organ is still not fully understood. In this review we highlight anatomical aspects of pancreatic innervation, techniques for pancreatic neuronal labeling, and approaches for imaging pancreatic innervation in vitro and in vivo.

Keywords: innervation, pancreatic ganglia, parasympathetic, sympathetic, vagus, nodose ganglia (ng), fluorescence imaging

\section{THE STATUS QUO OF PANCREATIC INNERVATION IS STILL BASED ON EARLY FINDINGS}

First accounts of pancreatic innervation go back to the times of Paul Langerhans, who described pancreatic islets as richly innervated clusters of cells (1869), Santiago Ramon y Cajal, who delineated the innervation of the exocrine acinar tissue (1891), and Ivan Pavlov, who showed the role of innervation in pancreas secretion (1887) (1). An understanding of pancreatic innervation came quite far by the first half of the twentieth century. A paper published in 1945 already gave a detailed description of parasympathetic, sympathetic, and afferent innervation, as well as its potential targets and physiological effects in both endocrine and exocrine pancreas (2). Most of the postulates in that review came from studying the effects of neuronal stimulation on endocrine and exocrine secretion and anatomical studies of neuronal degeneration, which were confirmed later with more modern techniques, such as tracing, immunohistochemistry, and electrophysiology.

Although our understanding of innervation patterns, neuronal chemical phenotype, innervation targets, and interspecies differences has advanced over time, conceptually it does not go far beyond of what was known in 1945. The scientific and clinical community still perceives pancreatic innervation as a classical autonomic network of robust competing sympathetic-parasympathetic efferent inputs and a still mysterious afferent sensory branch. The intricate details of peripheral transduction mechanisms, as well as the big picture of the neural circuitry of the pancreas and its role in the physiology of endocrine and exocrine pancreas are still elusive. Modern techniques of optical imaging have answered many questions in the neuroscience field and brought our 
understanding of neural circuity and connectivity in the brain to a completely different level. This review discusses approaches and challenges of structural and functional optical imaging of pancreatic innervation.

\section{STRUCTURAL AND FUNCTIONAL FEATURES OF PANCREATIC INNERVATION}

As the details of pancreatic innervation have been reviewed elsewhere (3-7), here we briefly go over some structural and functional features of innervation relevant for imaging, with an emphasis on neuroanatomical circuitry and neuronal phenotypes. The most intuitive way to segregate pancreatic innervation for practical imaging purposes is by the location of the neuronal soma: inside (intrinsic) or outside (extrinsic) of the pancreas (Figure 1).

\section{Intrinsic Pancreatic Innervation}

The intrinsic pancreatic innervation is a network of pancreatic neurons that cluster to form pancreatic ganglia and send unmyelinated projections to their targets in the endocrine and exocrine pancreas (8). Ganglia are dispersed throughout the pancreatic parenchyma and interlobular spaces, but are also present around some pancreatic islets, where they form neuroinsular complexes $(9,10)$. Anatomical heterogeneity and interspecies differences have been reported for pancreatic ganglia. The physiological significance of these differences, however, remains elusive $(9,11)$. Although the majority of pancreatic neurons is immunoreactive for cholinergic markers (ACh, VAChT, ChAT) and are thought to be postganglionic parasympathetic neurons $(5,12)$, only a fraction of them actually receives primary parasympathetic input $(12,13)$. In addition to cholinergic parasympathetic input, pancreatic ganglia also receive input from noradrenergic sympathetic neurons, substance P (SP)and calcitonin gene-related peptide (CGRP)- positive sensory neurons, and serotonergic and cholinergic enteric neurons (12, 1418). Thus, intrinsic neurons in pancreatic ganglia represent neuronal hubs that integrate multimodal extrinsic neuronal input and send an integrated message throughout the pancreas primarily via unmyelinated cholinergic projections (Figure 2). The histological and electrophysiological properties of pancreatic ganglia and their responsiveness to neurotransmitters, endocrine, and paracrine substances have been studied thoroughly [for a review, see $(3,5,6)$ ].

Most cholinergic terminals observed throughout the pancreas are thought to be projections of intrinsic pancreatic neurons (Figure 2). These fibers travel in the perivascular space and branch out to innervate the vasculature, endocrine cells of

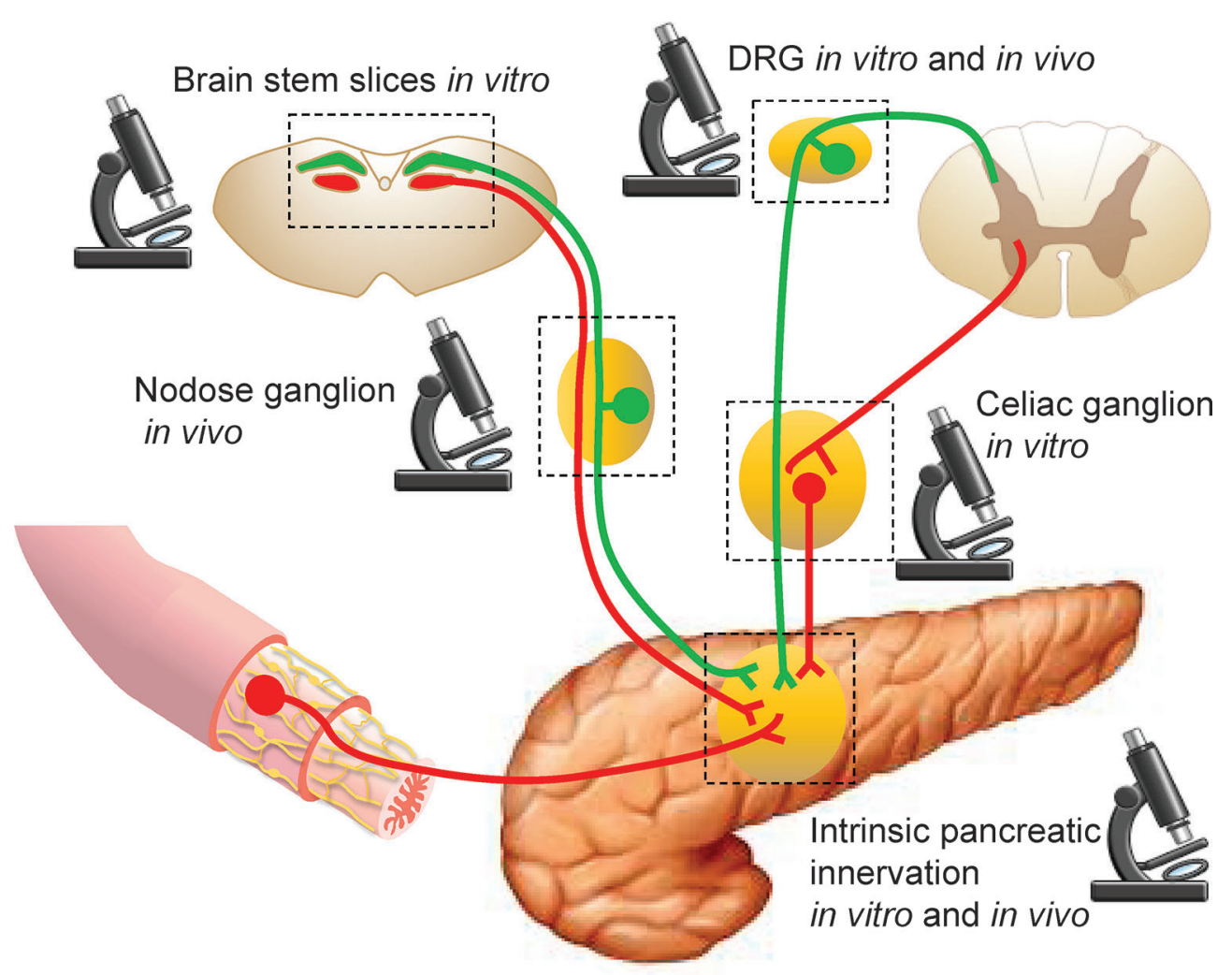

FIGURE 1 | Sites for imaging pancreatic innervation. Schematic representation of extrinsic sources of pancreatic innervation that converge on intrinsic pancreatic ganglia. Microscope icons indicate imaging sites. 

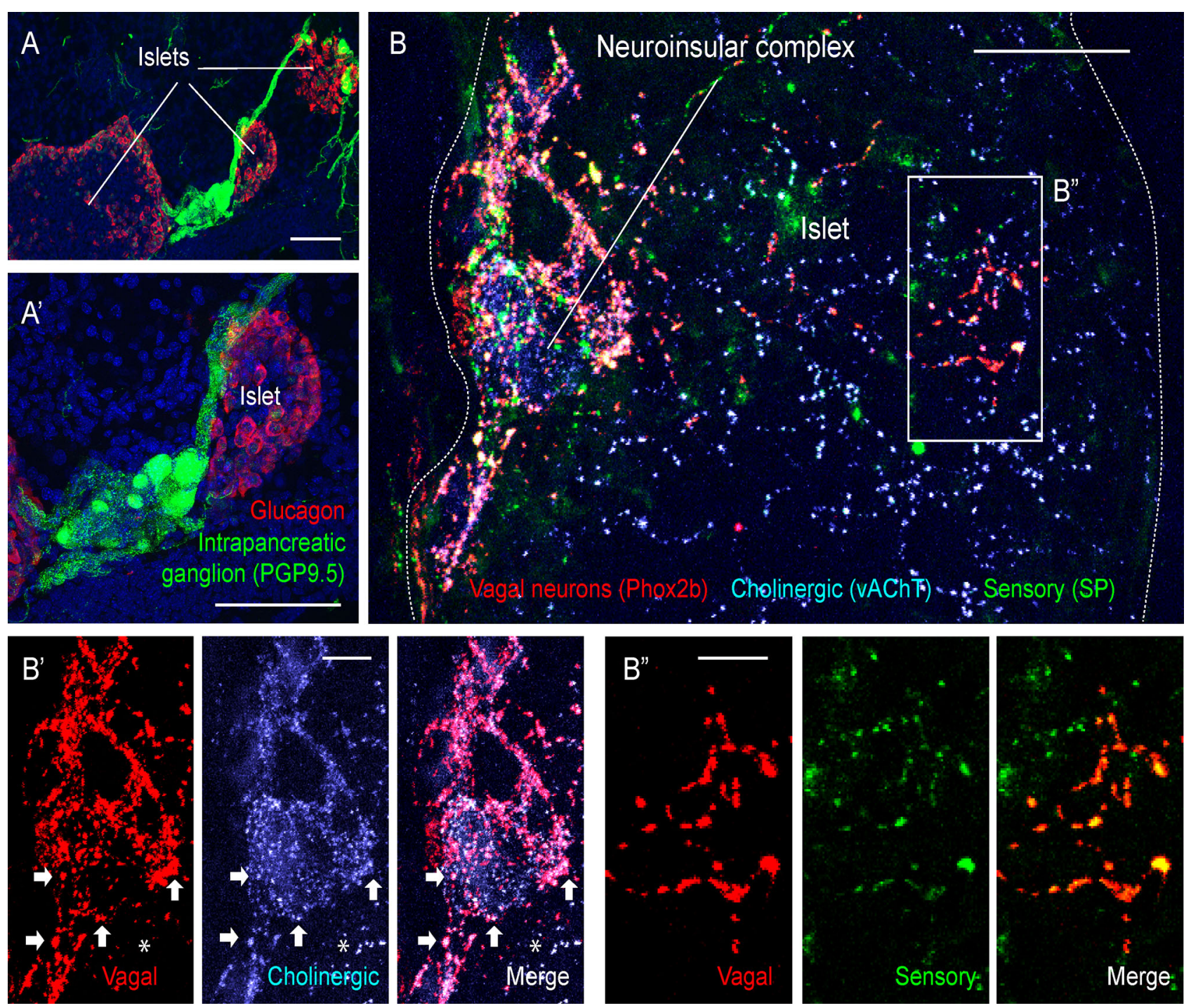

FIGURE 2 | Extrinsic and intrinsic cholinergic innervation of the endocrine pancreas (figure adapted and modified from Supplementary Figures 4, 5 in Makhmutova et al, 2020). (A, A') Mouse pancreatic section immunostained for the pan-neuronal marker PGP9.5 (green) and glucagon (red); scale bar 50 um. (B, B'”) Pancreatic section of a Phox $2 \mathrm{~b}-$ Cre-tdTomato floxed transgenic mouse, immunostained for red fluorescent protein (red), the sensory neuronal marker substance P (SP, green), and the cholinergic neuronal marker vesicular acetylcholine transporter (vAChT, blue). Inside the neuroinsular ganglion, Phox2b-positive varicosities colocalize with vAChT (B', arrows), indicating terminals of vagal preganglionic neurons; scale bar $20 \mu \mathrm{m}$. Outside of the neuroinsular ganglion (inside the islet), Phox $2 \mathrm{~b}-$ positive fibers colocalize with SP (B') but not with vAChT (B', asterisks), indicating vagal origin of sensory fibers and non-vagal origin of intrinsic cholinergic fibers; scale bar $5 \mu$ m.

pancreatic islets, exocrine acini, and the ductal system. Innervation of endocrine islets varies between species. In mouse islets, cholinergic fibers target $\alpha$ and $\beta$-cells, while in human islets endocrine cells are rarely contacted directly $(9,19)$. Interspecies differences raise many questions about postsynaptic targets, molecular mechanisms, and the physiological role of this innervation branch in the human endocrine pancreas.

Overall, stimulation of the intrinsic cholinergic system via multimodal extrinsic input is thought to activate the digestive state of the endocrine and exocrine pancreas by promoting vasodilation and increased secretion of insulin and exocrine enzymes. In parallel to its "rest and digest effects", cholinergic innervation is also an important player in mediating inflammatory responses in exocrine and endocrine pancreas $(20,21)$.

\section{Extrinsic Pancreatic Innervation}

Extrinsic neural input into the pancreas is composed of five autonomic branches: two efferent pathways - parasympathetic and sympathetic; two afferent pathways - vagal and spinal; and the entero-pancreatic axis. While primary parasympathetic neurons project exclusively to intrinsic ganglia, the other extrinsic branches also target pancreatic structures directly (12). 


\section{Parasympathetic Innervation}

Primary parasympathetic neurons with cell bodies in the dorsal motor nucleus of vagus (DMV) (12) travel in the vagus nerve and synapse exclusively in the pancreatic ganglia without targeting acinar or endocrine structures directly (12). Both primary parasympathetic and intrinsic pancreatic neurons are cholinergic. These different neural populations have distinct embryological origins and can be distinguished by embryonic markers. Vagal neurons (both afferent and efferent) are derived from the neurogenic placodes and can be visualized and accessed using the placodal-specific Phox2b-Cre mouse line (Figure 2). The neural crest derived neurons (intrinsic pancreatic, splanchnic, and enteric) can be visualized and accessed using the neural crest-specific Wnt1-Cre line $(22,23)$. It is generally assumed that parasympathetic innervation brings strong excitatory input to the intrinsic pancreatic neurons, presumably via nicotinic cholinergic receptors $(13,16,24-30)$. This input is intensely modulated by abundant extrinsic pathways at the level of the ganglia (31-35).
Activation of the parasympathetic system facilitates the secretion of digestive enzymes and glucose-lowering insulin and is thought to be responsible for preparing the organ for an increased digestive demand during the cephalic phase $(24,28,36-42)$.

\section{Sympathetic Innervation}

Primary sympathetic neurons reside in the intermediolateral column of the spinal cord and send projections to postsynaptic neurons of the perivertebral column and celiac ganglia via splanchnic nerves $(36,43)$. Noradrenergic projections of secondary sympathetic neurons enter the pancreas via mesenteric nerves and innervate pancreatic ganglia, vasculature, endocrine islets, ducts, and lymph nodes (Figure 3). Sympathetic activation leads to vasoconstriction, reduces exocrine secretion, and shifts endocrine secretion to the hyperglycemic state by lowering insulin and increasing glucagon levels $(44,45)$. In addition to this canonical sympathetic effect on pancreatic secretory function, several recent studies report an important interaction of sympathetic innervation
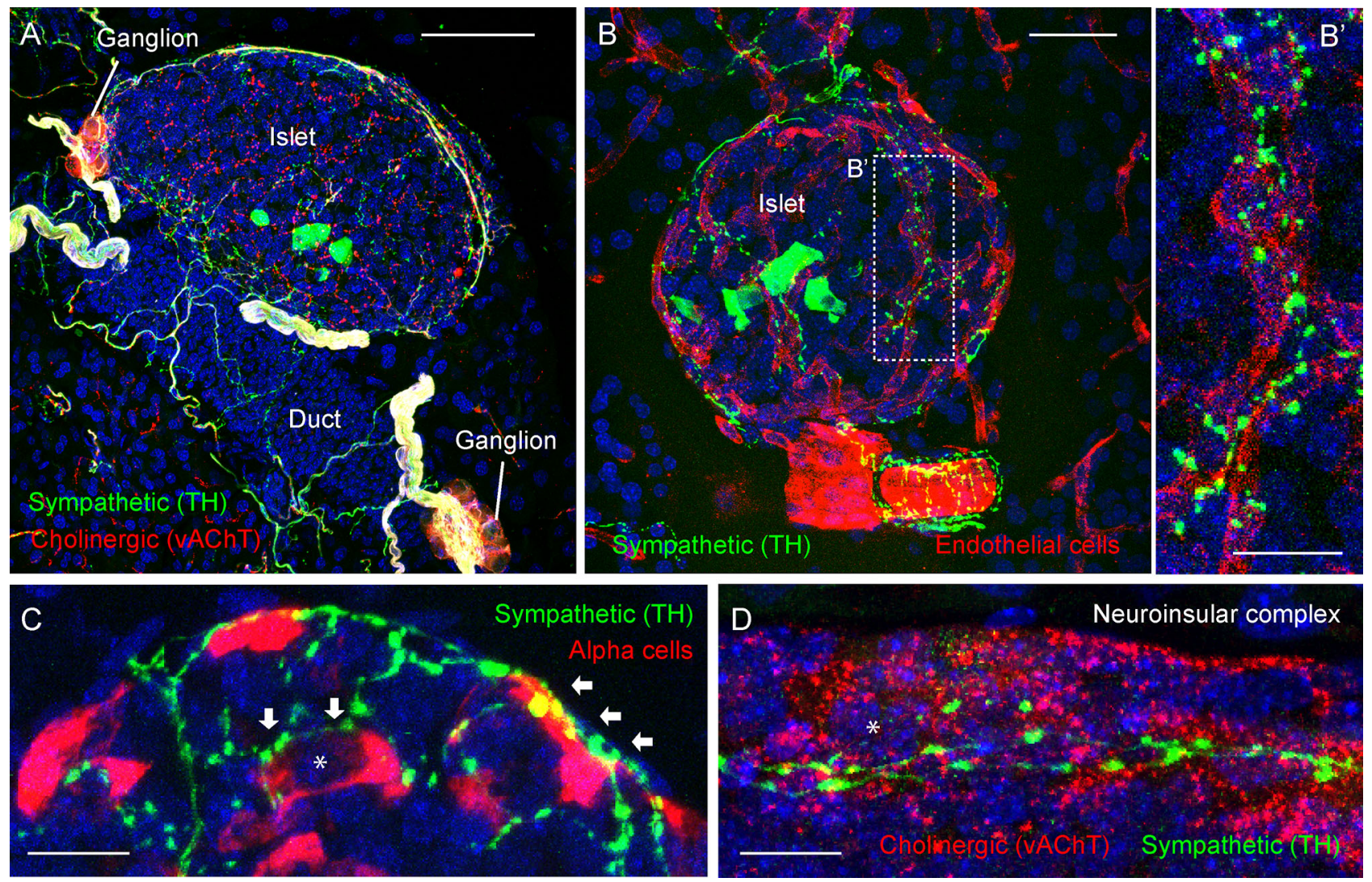

FIGURE 3 | Adrenergic innervation of the endocrine pancreas (photomicrographs are from experiments conducted by Dr. Joana Almaca, unpublished data). (A) Mouse pancreatic section immunostained for the sympathetic marker tyrosine hydroxylase (TH, green), the cholinergic marker vesicular acetylcholine transporter (vAChT, red), and DAPI (blue); scale bar 50 m. (B-B') Mouse pancreatic section immunostained for TH (green), endothelial marker CD31 (red), and DAPI (blue); scale bars $20 \mu \mathrm{m}$ (B) and $10 \mu \mathrm{m}$ (B'). (C) Mouse pancreatic section immunostained for TH (green), glucagon (red), and DAPI (blue); scale bar 10 $\mu \mathrm{m}$. (D) Mouse pancreatic section immunostained for TH (green), vAChT (red), and DAPI (blue); scale bar $10 \mu \mathrm{m}$. TH-positive fibers can be seen along the perivascular space of a large blood vessel (B) and intra-islet capillaries (B'). TH-positive varicosities contact endothelial vascular cells (B'), endocrine $\alpha$-cells (arrows in $\mathbf{C})$, and neurons within a neuroinsular complex (D). Asterisks denote an alpha cell (in $\mathbf{C}$ ) and a neuron (in D). 
with the pancreatic immune system $(14,46,47)$, which could be involved in the development of autoimmune diabetes (48).

\section{Sensory Innervation}

The pancreas receives both vagal and spinal sensory innervation. Vagal sensory neurons have cell bodies in the nodose ganglion and their projections travel alongside parasympathetic efferent fibers in the vagus nerve. Spinal sensory neurons originating bilaterally in the T9-T13 dorsal root ganglia travel alongside sympathetic fibers in splanchnic and mesenteric nerves. Substance P- and CGRPpositive sensory fibers are found throughout exocrine tissue and in the majority of pancreatic islets. Vagal sensory fibers project preferentially to pancreatic islets, indicating that the exocrine sensory component is primarily of spinal origin (Figure 2), although a contribution of spinal afferents to islet innervation has also been reported (49-51). Pathologies of the exocrine tissue such as cancer and pancreatitis are usually perceived as very painful and associated with increases in sensory innervation $(52,53)$. Diabetes and insulinomas, by contrast, seem to develop without significant sensory awareness. Moreover, vagal afferents in the pancreas are chemosensors, while spinal afferents are preferentially mechanosensitive $(14,54)$. This supports the idea that vagal and spinal sensory pathways carry different sensory modalities: the vagal being more of homeostatic nature, while the spinal being more nociceptive. A small percentage of intrinsic pancreatic neurons in mice and human pancreas are substance Ppositive, suggesting that the intrinsic pancreatic innervation might contain a sensory component. However, its sensory properties and physiological role remain elusive (11).

\section{Enteric Innervation}

The least studied and perhaps most intriguing neuronal input to the pancreas comes from the gut and is referred to as enteropancreatic innervation. Tracing studies show that the neuronal plexus of the stomach antrum and proximal duodenum extends to the pancreas, sending cholinergic and serotonergic projections preferentially to intrinsic ganglia, and more sparsely to the acinar tissue, endocrine cells, vasculature, and ducts. While it is difficult to distinguish enteric cholinergic input from vagal parasympathetic and intrinsic cholinergic fibers, serotonergic terminals in the pancreas seem to originate exclusively from the enteric nervous system. The effect of serotonergic innervation on pancreatic neurons is not straightforward since the latter express both excitatory [5HT3R (55)], and inhibitory [5HT1 $(55,56)]$, receptors and intraluminal intestinal stimulation has been shown to elicit both excitatory $(17,57)$ and inhibitory $(31)$ effects on pancreatic neurons and pancreas secretion. The enteric neuronal input to the endocrine pancreas has not been studied yet.

Intrinsic pancreatic neurons not only receive neuronal input from the gut (58), but also share anatomical similarities and embryonic origin with the enteric nervous system $(8,59,60)$. Throughout her early work, Kirchgessner has been advocating for a continuity of the pancreatic network with the enteric nervous system $(8,59,60)$. Moreover, vagotomy and sympathectomy have little effect on intrinsic pancreatic innervation (2), suggesting some degree of autonomy of the entero-pancreatic network from the central nervous system.

\section{CHALLENGES FOR STUDYING PANCREATIC INNERVATION}

In their early work on pancreatic innervation, Rudolf Heidenhein, Claude Bernard, and Ivan Pavlov acknowledged that studying pancreatic physiology and especially its innervation is by far a more challenging task than studying the innervation of other secretory glands $(1,61)$. They described the pancreas to be highly sensitive to surgical manipulations and experimental results to be extremely variable. Pavlov explained some of the experimental variability as a result of complex antagonistic interactions of innervation circuits and neuronal sensitivity to experimental conditions. Indeed, intrinsic pancreatic innervation receives multimodal input from all possible extrinsic innervation sources. Thus, output from intrinsic cholinergic neurons is a cumulative response to all extrinsic inputs, not a classical parasympathetic pathway. This is further complicated by the effects of extrinsic innervation on cardiovascular, exocrine, and endocrine systems, by the central nervous system feedback triggered by afferent innervation, and by local neuronal reflexes of the entero-pancreatic innervation.

The pancreas performs two very distinct yet essential functions: production of digestive enzymes by the exocrine compartment and secretion of the glucoregulatory endocrine hormones by its endocrine compartment. The pancreatic innervation is thus designed to control both exocrine and endocrine functions and target very distinct cell types. This heterogeneity, however, is very difficult to disentangle and make sense of.

The majority of axonal terminals inside the pancreas are nonmyelinated axons that are difficult to visualize. For instance, in their work on sympathetic innervation of the pancreas, Alm et al. noticed that sympathetic terminals around small capillaries were very thin (under $0.2 \mathrm{um}$ ) and contained unusually low levels of catecholamines (at least 100 fold lower of what has been observed in other tissues), making visualization of such fibers only possible after catecholamine-increasing treatment with L-Dopa or dopamine (62). To improve visualization of axonal terminals, a wide range of transgenic reporter mice is now available along with advanced viral neuronal tracing techniques.

Neuronal fibers in the pancreas do not form classical synapses with well-defined pre- and post-synaptic structures. Instead, they contain neurotransmitter-rich varicosities along their path and release their contents into the surrounding space affecting nearby target cells with appropriate receptors. This makes innervation effective in its ability to affect multiple targets simultaneously and introduces another level of physiological complexity but hinders the identification of postsynaptic targets and physiological effects.

Despite a wide body of literature on pancreatic innervation, many physiological and even anatomical questions remain unanswered and need to be addressed. Modern neuronal labeling and imaging techniques introduce means for overcoming many technical challenges and tackling those questions (Table 1). 
TABLE 1 | Open questions in the field of pancreatic innervation.

\begin{tabular}{|c|c|}
\hline $\begin{array}{l}\text { Innervation } \\
\text { Branch }\end{array}$ & Open questions in the field \\
\hline $\begin{array}{l}\text { Intrinsic } \\
\text { pancreatic } \\
\text { innervation }\end{array}$ & $\begin{array}{l}\text { - Differences in postganglionic cholinergic innervation of rodent and human endocrine pancreas raise many questions about postsynaptic targets, } \\
\text { molecular mechanisms, and the physiological role of this innervation branch in different species. } \\
\text { - The role of neuroinsular complexes and how they differ from other intrinsic ganglia that are not directly associated with endocrine islets remains } \\
\text { unknown. } \\
\text { - The anti-inflammatory effect of cholinergic innervation on resident macrophages has been proposed, but not confirmed. }\end{array}$ \\
\hline Sympathetic & $\begin{array}{l}\text { Adrenergic neurons innervate pancreatic islets and draining lymph nodes and are suspected to be important players in the pathogenesis of } \\
\text { autoimmune diabetes. The anatomical, physiological, and molecular properties of the interactions between sympathetic neurons and the local } \\
\text { components of the immune system requires further research. }\end{array}$ \\
\hline
\end{tabular}

\section{THE ARSENAL OF FLUORESCENT TOOLS TO STUDY PANCREATIC INNERVATION}

A significant research effort focuses on developing non-invasive imaging approaches with the use of magnetic waves, ultrasound, and radiation. These techniques, unfortunately, are not sensitive enough to visualize peripheral innervation. Fluorescence microscopy is one of the most informative experimental approaches in neuroscience today as it has capacity not only for structural visualization but also for functional imaging and optical manipulation of delicate neuronal structures. Limited light penetration, however, requires tissue isolation or quite invasive in vivo preparations that restrict this technique to the experimental niche. Here we will discuss fluorescent neuronal labeling and existing approaches of optically accessing intrinsic and extrinsic pancreatic innervation.

The neuroscience field offers a wide variety of tools for neuronal labeling. These include antibody-dependent techniques, genetically encoded reporters, and neuronal dyes for structural and functional imaging (Tables 2-4). While most neuronal markers are shared between different neuronal types, several reporters allow to distinctively label major peripheral branches of innervation: cholinergic (vAChT, ChAT), adrenergic (TH), and sensory (SP, CGRP, TRPV1) fibers (Table 2). Some neurons can further be distinguished by placodal or neural crest embryonic origin markers (Table 2). Sequencing studies of peripheral neuronal ganglia identify unique markers for peripheral innervation providing deeper molecular and genetic characterization for various neuronal types $(63,64)$. These markers are then used as guides for developing neuronal antibodies and generating transgenic reporters of selective neural pathways.

Antibody dependent neuronal labeling is a classical immunohistochemical approach for structural delineation of neuronal pathways. It is, however, limited by antibody specificity, tissue penetration, and epitope availability. While few neuronal markers are abundantly expressed (Pgp9.5, b-Tubulin) throughout a neuron, localization of most neuronal epitopes can vary along the neural process (i.e. axon). Thus, antibodies do not label neuronal shafts uniformly and do not always allow delineating fine neuronal projections and terminals. Although labeling of living nonpermeabilized neurons with antibodies against neuronal surface markers has been reported, it is very uncommon and only suitable to homogeneous neuronal cultures (65). Neuronal antibodies are preferentially suited for histology in fixed tissue.

Neurons can be targeted specifically by driving expression of fluorescent reporter proteins or transcriptional drivers under a neuron-specific promoter. This provides flexible access to neuronal populations for structural and functional imaging and for neuronal manipulations. Transgenic animal models that drive expression of either Cre-recombinase, fluorescent reporters, or $\mathrm{Ca}^{2+}$ indicators are available for the most common neuronal promoters (Tables 2, 3). Work with transgenic animals, however, requires validation of gene expression specificity since transgene expression does not always reflect endogenous promoter activity. Wonderful reviews summarize currently existing transgenic tools for targeting central and peripheral innervation $(66,67)$. Transgenic labeling is widely used for structural imaging because it allows efficient labeling of neuronal projections that greatly complements antibody-dependent neuronal labeling. To allow physiological recording of neuronal activity in vivo and in living pancreatic slices, neuronal promoters and Cre-drivers can be coupled to expression of the genetically encoded calcium indicator GCaMP. Analogously, transgenic expression of optogenetic (channelrhodopsin), chemogenetic (DREADD), and magnetogenetic (TRPV1-ferritin) receptors provides access to neuronal manipulation. 
TABLE 2 | Neuronal markers, antibodies, mouse transgenic lines, and promoters for neuronal labeling.

\begin{tabular}{|c|c|c|c|}
\hline Innervation type & Marker & Antibodies validated in the pancreas & Promoters/Transgenic lines \\
\hline $\begin{array}{l}\text { Cholinergic (primary } \\
\text { parasympathetic, primary } \\
\text { sympathetic, intrinsic pancreatic) }\end{array}$ & $\begin{array}{l}\text { ACh } \\
\text { vAChT } \\
\text { ChAT }\end{array}$ & 139103, Synaptic Systems & $\begin{array}{l}\text { N/A } \\
\text { SLC18A3-cre (PMID: 14502577) } \\
\text { ChAT-eGFP (Jax 007902) } \\
\text { ChAT-Cre (Jax 006410) }\end{array}$ \\
\hline $\begin{array}{l}\text { Adrenergic (secondary } \\
\text { sympathetic) }\end{array}$ & $\mathrm{TH}$ & AB152, Millipore & TH-Cre (Jax 008601) \\
\hline $\begin{array}{l}\text { Peptidergic-sensory (vagal } \\
\text { afferents, spinal afferents, intrinsic } \\
\text { sensory) }\end{array}$ & $\begin{array}{l}\text { SP } \\
\text { CGRP } \\
\text { TRPV1 } \\
\text { 5HT3R } \\
\text { Pirt }\end{array}$ & $\begin{array}{l}\text { MAB356, Millipore } \\
\text { BML-CA1134, Enzo } \\
\text { Alomone labs ACC-030 }\end{array}$ & $\begin{array}{l}\text { Tac1-Cre (Jax 021877) } \\
\text { CALCA-Cre/eGFP (Jax 033168) } \\
\text { TRPV1-Cre (Jax 017769) } \\
\text { 5HT3R-GFP (PMID 19095802) } \\
\text { 5HT3R-Flpo (Jax 030755) } \\
\text { Pirt-GCaMP3 (JHU C13628) } \\
\text { Pirt-Cre (JHU C13783) }\end{array}$ \\
\hline Serotonergic (enteric) & $5 \mathrm{HT}$ & & $\mathrm{N} / \mathrm{A}$ \\
\hline $\begin{array}{l}\text { Placodal-derived (vagal afferent } \\
\text { and efferent) }\end{array}$ & Phox2b & & Phox2b-Cre (Jax 016223) \\
\hline $\begin{array}{l}\text { Neural Crest-derived } \\
\text { Pan-neuronal markers }\end{array}$ & $\begin{array}{l}\text { Wnt1 } \\
\text { b3Tub } \\
\text { Pgp9.5 } \\
\text { Thy1 } \\
\text { Snap25 } \\
\text { Synaptophysin (Syp) }\end{array}$ & $\begin{array}{l}\text { MRB-435P, Covance } \\
\text { \#233003, Synaptic Systems }\end{array}$ & $\begin{array}{l}\text { Wnt1-Cre (Jax 022137) } \\
\text { TUBB3-eGFP (MGl:4847518) } \\
\text { UCHL1-eGFP (Jax 022476) } \\
\text { Thy1-Cre (Jax 006143) } \\
\text { Snap25-GCaMP6 (Jax 025111) } \\
\text { Syp promoter } \\
\text { RC::FPSit (Jax 030206) } \\
\text { Ai34D (Jax 012670) }\end{array}$ \\
\hline & $\begin{array}{l}\text { Synapsin (Syn) } \\
\text { Acetylated tubulin } \\
\text { NeuN } \\
\text { S100 } \\
\text { NF200 } \\
\text { cFos }\end{array}$ & $\begin{array}{l}\text { Cell Signaling Technology } 5297 \\
\text { \#106011C5, Synaptic Systems } \\
\text { T6793, Sigma } \\
\text { ab52642, Abcam } \\
\text { Sigma-Aldrich N4142 } \\
\text { \#226003, Synaptic Systems }\end{array}$ & $\begin{array}{l}\text { Syn1-Cre (Jax 003966) } \\
\text { hSyn - most common AAV promoter on AddGene } \\
\text { TUBA1A promoter } \\
\text { RBFOX3 promoter } \\
\text { S100b-Cre (Jax 014160) } \\
\text { TRAP2 (Jax 030323) }\end{array}$ \\
\hline
\end{tabular}

TABLE 3 | Examples of Cre-dependent reporter mouse lines for neuronal labeling.

\begin{tabular}{|c|c|c|c|}
\hline & Reporter line & Stock number & Use \\
\hline \multirow[t]{3}{*}{ Structural reporters } & ROSA26-eGFP & Jax 004077 & eGFP reporter \\
\hline & Ai6 & Jax 007906 & Ubiquotous expression of ZsGreen1 reporter throughout dendrites and long axons \\
\hline & Ai14 & Jax 007914 & Ubiquotous expression of tdTomato reporter throughout dendrites and long axons \\
\hline \multirow[t]{3}{*}{ Functional reporters } & Ai95 & Jax 028865 & $\mathrm{Ca}^{2+}$ indicator GCaMP6f (fast response kintetics) \\
\hline & Ai96 & Jax 028866 & $\mathrm{Ca}^{2+}$ indicator GCaMP6s (slow response kinetics) \\
\hline & TRAP2 & Jax 030323 & Cre-dependent reporter expression in active neurons expressing immediate early gene cFos \\
\hline \multirow[t]{3}{*}{ Neuro-modulators } & Ai32 & Jax 012569 & Channelrhodosin-2/eYFP fusion protein for optogenetic stimulation \\
\hline & RC::FPDi & Jax 029040 & Inhibitory DREADD-mCherry fusion protein for pharmacogenetic inhibition \\
\hline & RC::L-hM3Dq & Jax 026943 & Excitatory DREADD-mCherry fusion protein for pharmacogenetic stimulation \\
\hline
\end{tabular}

Viral delivery of transgenes allows targeting neurons specifically with improved spatial and temporal resolution (68). Pancreatic neurons can be transfected by injecting the virus into the pancreatic parenchyma (69), infusing the pancreas with the virus through the common bile duct (70), or by less specific injections into extrinsic neuronal ganglia. Viruses are excellent for long range neuronal tracing and neuronal manipulation in vivo and can potentially be used with pancreatic slices in vitro. Because pancreatic tissues are very heterogeneous, neuronal specificity of viral transfection requires the use of neuronspecific or Cre-dependent viral vectors and viral particles with increased neuronal tropism.
Being replaced by transgenic animal models and viral tracing approaches, conventional neuronal dyes are unjustly placed on the sideline of neuroscience research today. Compared to transgenic reporters, neuronal dyes are relatively inexpensive and allow acute neuronal labeling across different species, which can be especially advantageous for assessing innervation in human tissues (e.g. in living pancreas slices from human pancreatic donors). Cytoplasmic and membrane dyes are useful tools for structural assessment of innervation and can be used for long-range neuronal tracing in vivo, local neuronal labeling in living pancreatic tissue slices, and even in fixed tissues (in the case of DiI, Table 4). Functional neuronal dyes allow to 
TABLE 4 | Conventional dyes for neuronal labeling.

\begin{tabular}{|c|c|c|c|}
\hline & Neuronal dye & Labeling properties & Cell loading \\
\hline \multirow[t]{2}{*}{ Cytoplasmic } & Hydrazides and Biocytins & $\begin{array}{l}\text { Intracellular } \\
\text { bidirectional tracer } \\
\text { Assesment of gap junctions }\end{array}$ & $\begin{array}{l}\text { enter cells by microinjection and iontophoresis, may cross gap } \\
\text { junctions }\end{array}$ \\
\hline & Dextran conjugates & $\begin{array}{l}\text { Intracellular } \\
\text { bidirectional tracer }\end{array}$ & $\begin{array}{l}\text { enter cells by microinjection and through resected neuronal } \\
\text { terminals }\end{array}$ \\
\hline \multirow{3}{*}{$\begin{array}{l}\text { Membrane- } \\
\text { bound }\end{array}$} & Choleratoxin subunit B (CTB) & membrane-bound bidirectional tracer & Binds to plasma membrane glycosphingolipids \\
\hline & $\begin{array}{l}\text { Lectins (WGA, Phaseolus } \\
\text { Vulgaris, DBA, GS) }\end{array}$ & $\begin{array}{l}\text { membrane-bound bidirectional tracer } \\
\text { have limited trans-synaptic labeling capacity (WGA) }\end{array}$ & Bind various plasma membrane carbohydrates \\
\hline & Dil & $\begin{array}{l}\text { Lateral diffusion in plasma membrane } \\
\text { Bidirectional tracer } \\
\text { Can be used in live or fixed tissue }\end{array}$ & Lipohilic dye, incorporates into lipid bilayer \\
\hline \multirow[t]{3}{*}{ Functional } & AM and FM dyes & $\begin{array}{l}\text { Non-fluorescent in aqueous solution, become } \\
\text { fluorescent upon internalization }\end{array}$ & $\begin{array}{l}\text { Enter cells by endocytosis or through non-selective ion channels } \\
\text { Internalization can be activity-dependent }\end{array}$ \\
\hline & $\begin{array}{l}\text { Calcium indicator dyes (Fluo-4, } \\
\text { Fura-2) }\end{array}$ & $\begin{array}{l}\text { Become fluorescent upon } \mathrm{Ca}^{2+} \text { binding, } \\
\text { Activity-dependent }\end{array}$ & $\begin{array}{l}\text { Esterified dyes are membrane permeable, trapped inside cells } \\
\text { after cytoplasmic de-esterification }\end{array}$ \\
\hline & $\begin{array}{l}\text { Voltage-sensetive dye (FluoVolt, } \\
\text { ANEP) }\end{array}$ & $\begin{array}{l}\text { Become fluorescent upon changes in electrical } \\
\text { potential }\end{array}$ & $\begin{array}{l}\text { Bind plasma membranes (FluoVolt), membrane-permeable } \\
\text { (ANEP) }\end{array}$ \\
\hline
\end{tabular}

monitor neuronal activity either by binding intracellular signaling molecules $\left(\mathrm{Ca}^{2+}\right.$ and cAMP indicators), responding to changes in electrical potential (membrane voltage dyes), or by activity-dependent internalization of the dye (AM and FM dyes, Table 4). The majority of conventional dyes, however, have limited neuronal specificity and thus must be applied locally.

\section{STRUCTURAL IMAGING OF INNERVATION IN FIXED PANCREAS TISSUES}

In the field of islet biology, the most common histological approach for studying endocrine cells involves widefield imaging of thin tissue sections $(<10 \mu \mathrm{m})$. This, however, is not suitable for studying neuronal projections that with elaborate three-dimensional terminal trees. Thicker pancreatic cryosections $(40-60 \mu \mathrm{m})$ allow sufficient antibody penetration, excellent access to confocal imaging, and easy histological processing on the slide without harsh clearing protocols (Figures 2, 3). Confocal imaging of thick pancreatic cryosections allowed delineating parasympathetic and sympathetic innervation, reconstructing axonal terminals in $3 \mathrm{D}$ in human and mouse pancreatic tissues with excellent spatial resolution, and identifying their potential postsynaptic targets $(19,22)$.

The now popular technique of organ clearing allowed whole pancreas imaging and $3 \mathrm{D}$ reconstruction of entire pancreatic innervation. This technique is especially informative in understanding innervation continuity and heterogeneity throughout the whole pancreas and gives a better perspective on connectivity between endocrine and exocrine compartments $(9,11,71-74)$. While advantageous for studying neuronal connectivity and histology of large neuronal structures such as neuronal ganglia and large neurites, this approach is not always adequate for analyzing fine neuronal terminals and their postsynaptic targets due to limited subcellular resolution. Moreover, tissue clearing involves use of harsh organic compounds which may interfere with epitope preservation, and usually requires lengthy incubations (days to weeks).

\section{LIVE IMAGING OF PANCREATIC INNERVATION}

Live imaging of innervation requires making target tissues visually accessible without significantly interfering with tissue physiology. Intrinsic pancreatic innervation and extrinsic neuronal terminals can be imaged at the level of the pancreas either in the intact pancreas or in living pancreatic slices. Extrinsic pancreatic innervation can also be imaged outside of the pancreas in corresponding extrinsic ganglia. Innervation of pancreatic islets can be studied longitudinally after transplantation into the anterior chamber of the eye. To avoid all the hurdles of exposing innervation in rodent models, pancreatic innervation can be studied in transparent animal models such as zebra fish. And finally, islet innervation can be studied in artificial setting of coculture of pancreatic islets and primary neurons.

\section{In Vivo Imaging of Intact Pancreas (Exteriorized Pancreas and Intravital Window)}

The pancreas can be partially exteriorized and imaged acutely in anesthetized animals (46, 75-77). For gaining longitudinal optical access to the pancreas, several recent studies report the use of an intravital window installed into the abdominal wall. Unlike a very stable cranial window attached to the scull, the abdominal window is attached to the muscle, is more prone to movement and requires additional fixation of the pancreas to stabilize the field of view. Pancreas exteriorization and abdominal window provide access for imaging superficial structures at cellular resolution. Although innervation has never been imaged at the level of the intact pancreas in vivo, several studies report effective imaging of pancreatic endocrine cells, immune cells, and vasculature $(46,75-77)$, suggesting that this approach can potentially be used for imaging superficial large neuronal structures such as pancreatic ganglia and neuroinsular complexes. However, due to limitations of optical tissue penetration and residual tissue movement, this technique is not ideally suited for imaging fine neuronal projections and terminals. 


\section{Living Pancreatic Slices}

Mouse and human pancreatic tissue slices are becoming a common tool for studying endocrine, exocrine, and vascular physiology (78-81). Living pancreatic slices provide optical access to deep pancreatic structures with a partially preserved native microenvironment. Slices with a thickness of 120-150 um can be almost entirely visualized with confocal microscopy, allowing high resolution imaging of fine neuronal terminals [Figure 4 (14)]. Many neuronal terminals in the slice, however, end up being cut from their neuronal soma and therefore might maintain their responsiveness for a short period of time or change their physiological properties. Moreover, labeling efficiency of fine neuronal projections in the pancreas remains problematic. In our experience, animals expressing a knock in GCaMP3 gene under the Pirt promoter have strongly labeled pancreatic terminals (Figure 4), while terminals could not be visualized in Pirt-CreGCaMP6 mice (14). Despite these challenges, this approach has proven itself effective for imaging various pancreatic cell types, including neuronal terminals, and holds a lot of potential for functional imaging of pancreatic innervation.
Functional imaging of living tissue slices from human donors is an invaluable resource for studying physiology of human pancreas. Although functional studies of human pancreatic innervation have not been reported yet, we assume it is possible but challenging due to difficulties in neuronal labeling and the high neuronal vulnerability to ischemia with its associated anoxia.

\section{Eye Model for Studying Islet Transplants}

A creative attempt that is complementary to imaging the intact pancreas and pancreatic tissue slices is the "eye model" of noninvasive longitudinal imaging of pancreatic islets $(82,83)$. In this approach, islets isolated from the donor (mouse or human) are transplanted into the anterior chamber of the eye of a recipient mouse. Islets engraft on the iris of the eye, vascularize and establish innervation (Figure 5). The eye, in this case, plays a role as a natural imaging chamber and allows noninvasive longitudinal imaging with minimal movement artifacts in headfixed anesthetized animals. Interestingly, once engrafted, the iris' autonomic nerves innervate the islet. The newly developed islet
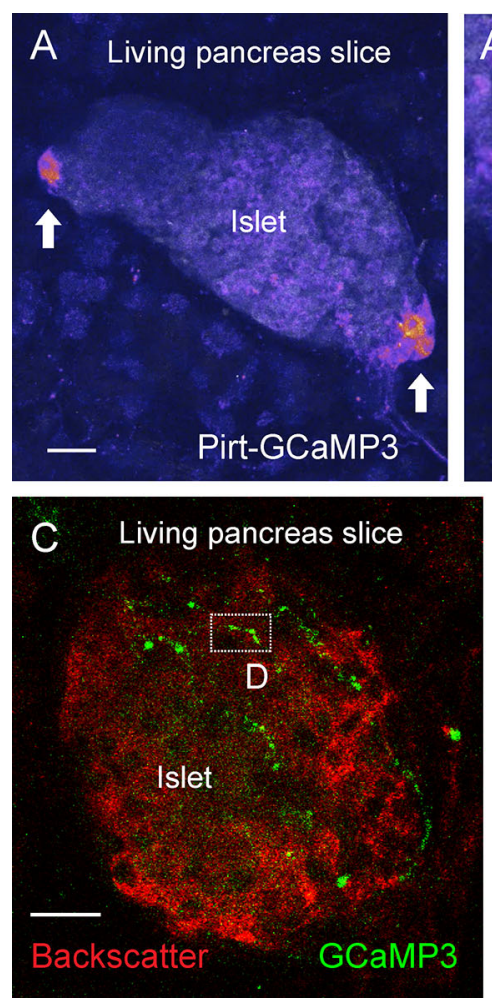
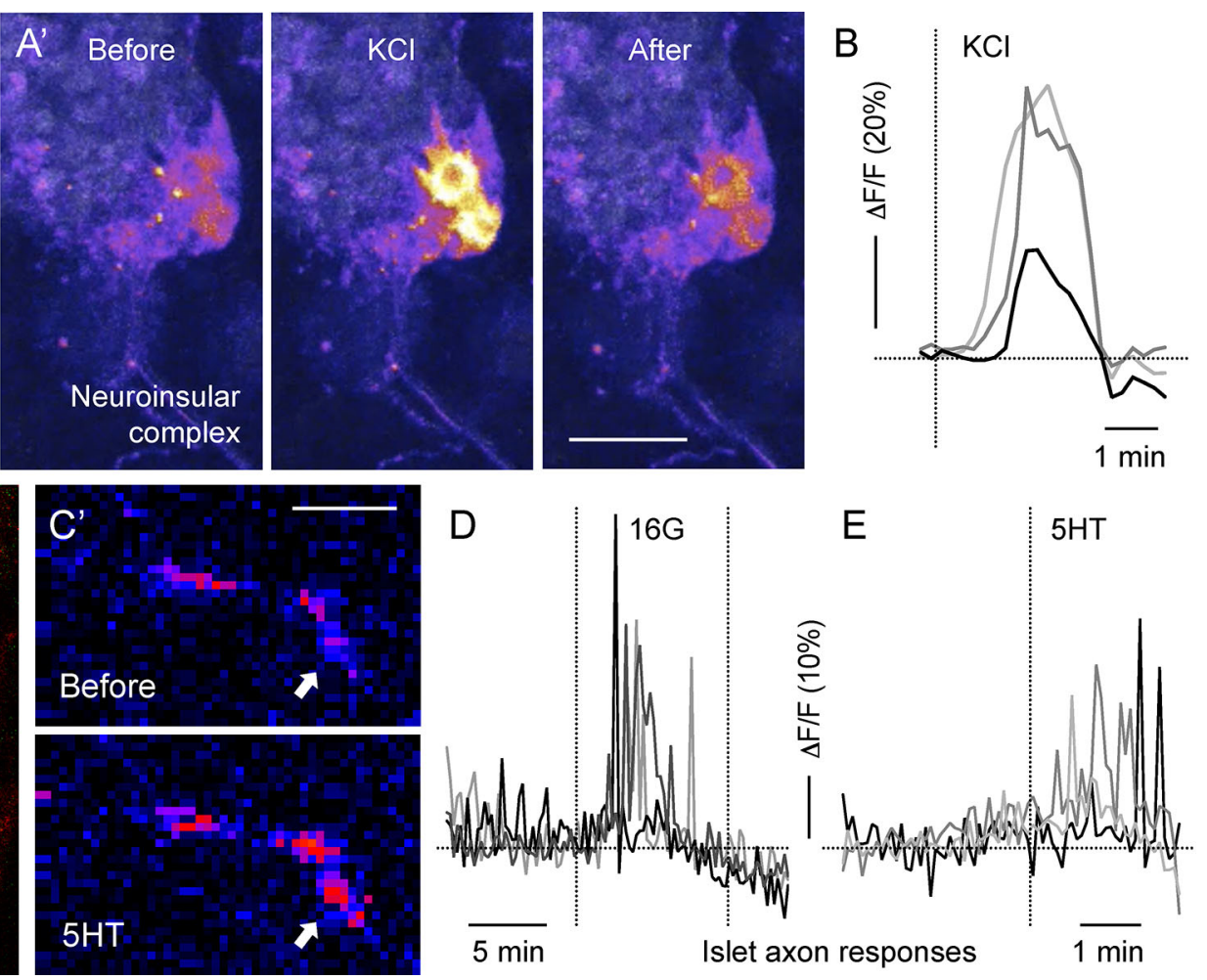

Islet axon responses

$1 \mathrm{~min}$

FIGURE 4 | Living mouse pancreatic slices for imaging $\mathrm{Ca}^{2+}$ activity in neuroinsular ganglia and in sensory axonal terminals [photomicrographs are from experiments conducted by Dr. Jonathan Weitz, (A, B) unpublished data, (C-F) adapted and modified from Figure 6 in Makhmutova et al, 2020]. (A, C) Z-stacks of confocal images of living pancreatic slices from Pirt-GCaMP3 mice. (A) A representative islet containing neuroinsular ganglia (arrows), with GCaMP3 fluorescence and islet backscatter shown in pseudocolor scale; scale bar $10 \mu \mathrm{m}$. (A') Sequential images of the neuroinsular ganglion shown in $\mathrm{A}$, displaying a Ca ${ }^{2+}$ response to $\mathrm{KCl}$ (25 mM). (B) Representative traces of mean fluorescence intensity changes over baseline ( $\delta$ F/F) in the neuroinsular ganglion shown in (A'), demonstrating neuronal responses to $\mathrm{KCl}$ stimulation. (C) Representative islet containing GCaMP3-expressing sensory axonal terminals (green). Islet backscatter is shown in red; scale bar $20 \mu \mathrm{m}$. (C') Sequential images of the sensory fiber shown in C (box), displaying a $\mathrm{Ca}^{2+}$ response to $5-\mathrm{HT}$ (50 $\left.\mu \mathrm{M}\right)$. The arrow points to a region showing an increase in GCaMP3 fluorescence (pseudocolor scale); scale bar $5 \mu \mathrm{m}$. (D, E) Representative traces of mean fluorescence intensity changes over baseline ( $\delta \mathrm{F} / \mathrm{F}$ ) in sensory fibers, demonstrating responses to an increase in glucose concentration from $3 \mathrm{mM}$ to $16 \mathrm{mM}$ (16G, D) and to 5-HT (50 $\mu \mathrm{M})$ stimulation (E) 

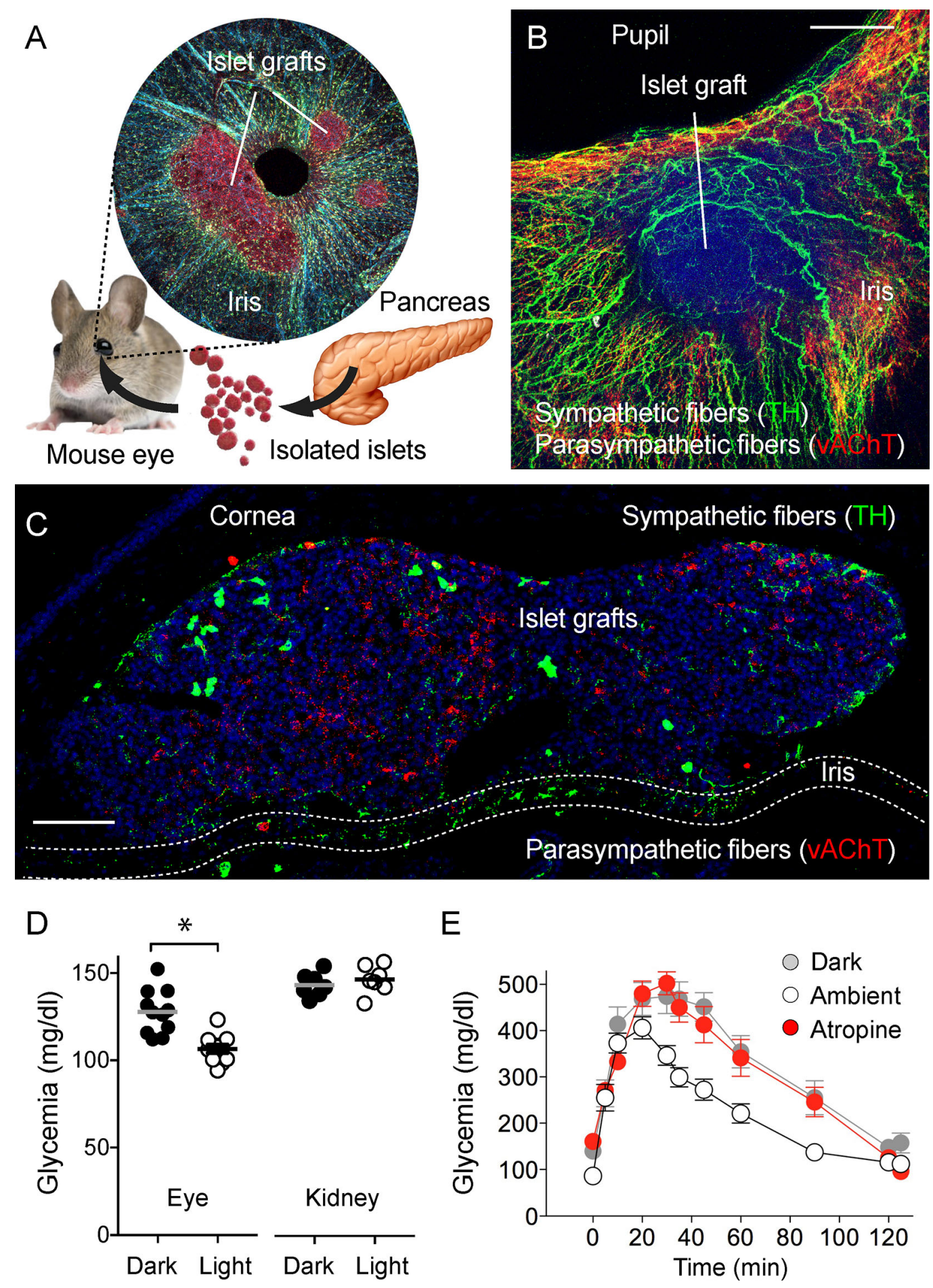

FIGURE 5 | Eye model for imaging innervation of pancreatic islet grafts [photomicrographs are from experiments conducted by Dr. Rayner Rodriguez-Diaz (A-C, unpublished data], data in (D) and (E) adapted and modified from Figure 4 in Rodriguez-Diaz et al., 2012). (A) Schematic representation of islet transplantation into the anterior chamber of the eye. Islets isolated from the pancreas are transplanted into the mouse eye. Microphotograph of an iris wholemount with islet grafts.

(B) Z-stack of confocal images of a wholemount of the mouse iris with an islet graft immunostained for TH (green) and vAChT (red); scale bar $50 \mu \mathrm{m}$. (C) Confocal image of a cross-section of the mouse eye showing two islet grafts, stained for TH (green), vAChT (red), and DAPI (blue); scale bar $50 \mu \mathrm{m}$. (D) Plasma glucose levels in mice transplanted with islets in the anterior chamber of the eye or under the kidney capsule, in ambient light or in the dark ("${ }^{*}<0.05$, paired Student's t-test). (E) Glucose excursion during an IPGTT of transplanted mice performed in the dark (gray symbols), ambient light (open symbols), or in ambient light after topical application of the muscarinic receptor antagonist atropine (red symbols). 
innervation thus becomes dependent on the pupillary light reflex. When the light is on, parasympathetic stimulation triggers pupillary constriction and induces insulin secretion in engrafted islets. In dark ambient conditions, sympathetic activation triggers the pupil to dilate, and insulin secretion returns back to baseline levels (84). While the peripheral innervation of the islet graft and responses of the graft to neuronal stimulation are physiologically accurate, the neuronal pathways are not linked to the autonomic centers innervating the pancreas.

\section{Imaging Extrinsic Nuclei and Ganglia That Send Neuronal Projections to the Pancreas}

Axonal terminals of extrinsic innervation can be studied at the level of the pancreas using the approaches listed above. Extrinsic innervation can also be examined at the level of the neuronal cell bodies that reside in brain nuclei or peripheral ganglia outside of the pancreas.

The dorsal vagal complex of the brainstem includes dorsal motor nucleus of vagus (DMV), composed of primary parasympathetic neurons, and the nucleus of the solitary tract (NTS), the region that receives sensory input from vagal sensory neurons. This site is believed to be an integral part of the vago-vagal reflex. Although the existence of this reflex has been confirmed for the exocrine pancreas (85), and has been proposed for the endocrine pancreas, a pancreasspecific pathway in the dorsal vagal complex remains to be described. Neurons of the dorsal vagal complex can be labeled by tracing from the pancreas $(14,69,86)$ or by activity-dependent genetic labeling (87) induced by pancreas-specific stimulation. Once labeled, these neurons can be studied using imaging approaches in vivo or in brainstem slices $(88,89)$.

Celiac ganglia are the largest ganglia in the peripheral nervous system and are the major site of postganglionic sympathetic neurons innervating the pancreas $(43,90)$. Although sympathetic neurons have been extensively studied morphologically and electrophysiologically (91), a characterization of sympathetic subpopulations based on innervation targets is still lacking. Perhaps investigators were not motivated to do so because of the common notion that sympathetic stimulation induces a uniform inhibitory effect on digestion. Recent studies, however, are revealing

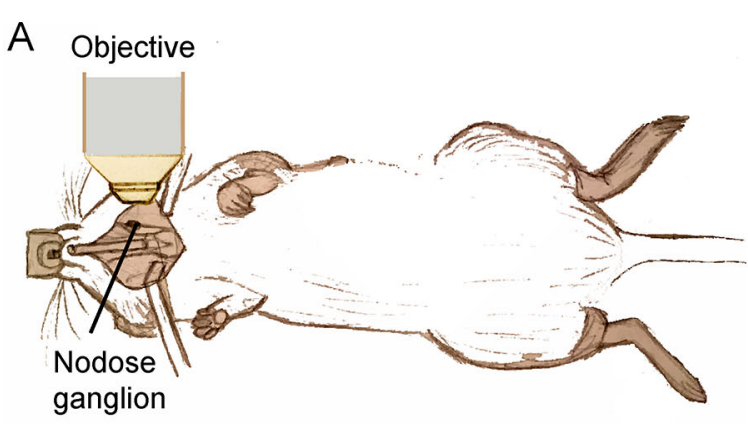

D Intraductal stimulation of the pancreas
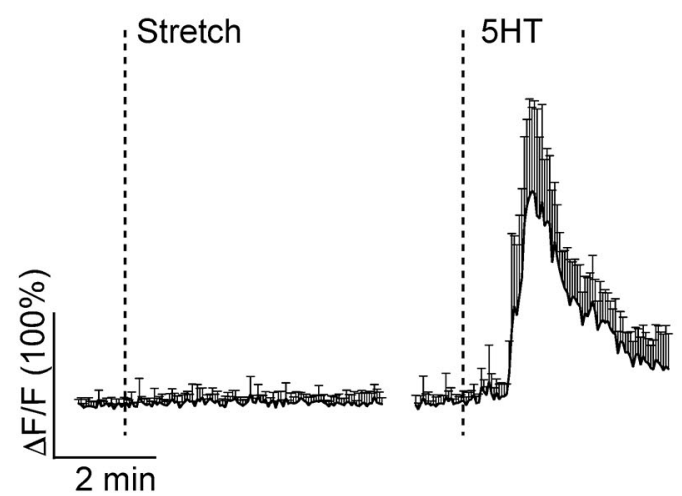
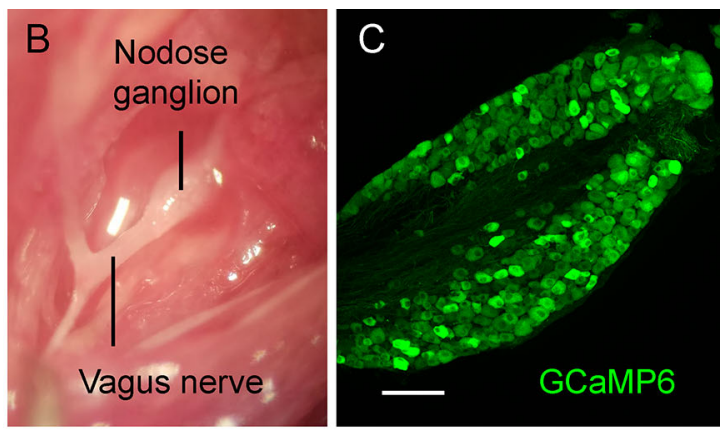

\section{E Pharmacogenetic stimulation of $\beta$-cells}
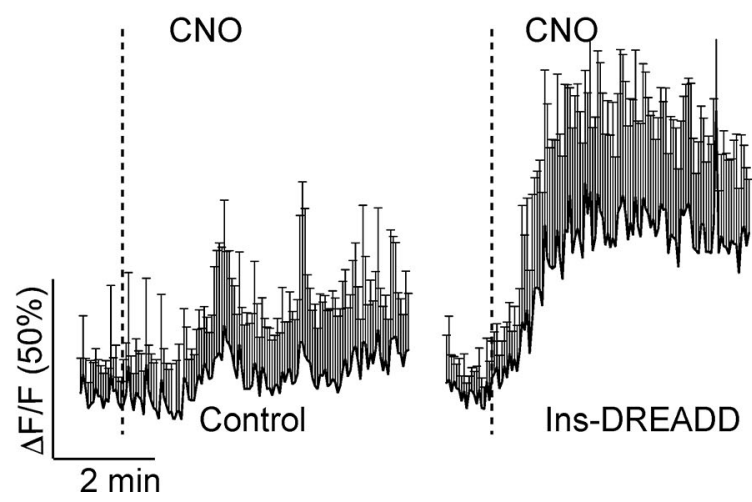

FIGURE 6 | In vivo imaging of the mouse nodose ganglion (figure adapted and modified from Figures 3, 4 in Makhmutova et al, 2020). (A) Drawing illustrates the experimental set up, where the intact nodose ganglion is exposed for $\mathrm{Ca}^{2+}$ imaging under a confocal microscope. (B) Photomicrograph of the exposed nodose ganglion. (C) Section of the nodose ganglion from a Pirt-GCaMP6 mouse. (D) Average traces of fluorescence intensity changes over baseline ( $\delta$ F/F) in nodose ganglion neurons, demonstrating neuronal responses to stretch (intraductal pancreatic infusion with saline, $300 \mu \mathrm{l} / \mathrm{min}$ ) or intraductal application of 5 - $\mathrm{HT}$ (1 $\mathrm{mM}$, $150 \mu \mathrm{l} / \mathrm{min})$. (E) Average traces of fluorescence intensity changes over baseline ( $\mathrm{F} / \mathrm{F})$ in nodose ganglion neurons, demonstrating neuronal responses to pharmacogenetic stimulation of $\beta$-cells by i.p. injection of clozapine nitric oxide $(\mathrm{CNO}, 5 \mathrm{mg} / \mathrm{kg})$ in control mice or in mice expressing designer receptor activated by designer drug (DREADD) exclusively in $\beta$-cells. Shown is the mean trace of 10 neurons (+/- SEM). 
an important interaction of sympathetic nerves with the immune system, particularly with immune cells of lymph nodes associated with the pancreas $(14,46,47)$. A characterization of postganglionic sympathetic neurons therefore becomes physiologically and even clinically relevant. Although in vivo imaging approaches of the celiac ganglia have not been developed yet due to its inaccessible anatomical localization, explants of the ganglia can be studied morphologically and physiologically using immunohistochemical and calcium imaging approaches in combination with retrograde tracing from the pancreas.

Nodose and dorsal root ganglia (DRGs) are respectively the sensory ganglia of the vagal and spinal sensory pathways that receive input from the pancreas (50). Because sensory innervation has been attributed a role in the maintenance of glucose homeostasis $(49,92,93)$, decoding the signals at the level of the primary sensory neuron becomes an essential step in understanding the type of information the pancreas is transmitting to the brain via autonomic nerves. By recording activity of nodose ganglion neurons in vivo, we showed that these neurons are pancreatic chemosensors, responsive to selective stimulation of $\beta$-cells, presumably via serotonin-dependent mechanism, and are not sensitive to mechanical stimulation of the pancreas (Figure 6) (14) The sensory modality transmitted through the DRG remains to be discovered, but in vivo imaging of the DRG is technically challenging (94).

\section{In Vivo Imaging of Pancreatic Innervation in Zebra Fish (PMID: 29916364)}

The zebra fish is an experimental model that has been used for studying multiple aspects of pancreas biology including pancreatic development, endocrine cell regeneration, vascularization and innervation (95-97). Its transparency during larval stages makes the zebra fish a great model for functional live imaging. Easy access for genetic manipulations allows efficient multi transgenic labeling of neurons and other pancreatic cell types simultaneously. Also, a short lifespan facilitates studies on development. Time-lapse in vivo imaging of zebra fish allowed delineating the sequence of events that leads to parasympathetic innervation of the pancreatic islet and measuring in real time changes in the endocrine cell mass in response to targeted neuronal ablation (97). Although advantageous for imaging pancreatic innervation and having multiple physiological and morphological similarities to the mammalian systems, processes learned in the zebra fish model need to be analyzed through the prism of interspecies differences.

\section{Co-Culture of Neurons and Pancreatic Cells}

Studying synaptic transmission between a neurite and its postsynaptic target is a challenging task in the in vivo experimental setting. It is very difficult to access and manipulate the selected individual synaptic interaction. Furthermore, the local physiological mechanism cannot be uncoupled from the confounding systemic effects innervation has. The interactions between nerves and its targets can be better addressed in vitro (Figure 7). A beautiful example of synapse formation in vitro has been shown by culturing trigeminal sensory neurons with intestinal enteroendocrine cells (98). An example closer to islet biologist are studies showing that sympathetic neurons cultured with pancreatic islets triggered changes in islet cytoarchitecture inducing $\beta$-cell migration (99). Co-culture experiments might be challenging as culturing conditions need to accommodate the needs of very distinct cell types, and primary neuronal cultures are famous for being difficult to maintain in vitro.

\section{CONCLUDING REMARKS}

Pancreatic tissues and their innervation have been studied for decades using classical histology in combination with electrophysiology. Those laborious methods are being replaced by modern optical imaging techniques combined with precise genetic cellular labeling. While the pancreas biology field has implemented the approaches needed to access the pancreas optically (e.g. exteriorized pancreas, living pancreas slices),

\section{A Islet Stimulation $\mathrm{Ca}^{2+}$ maging from neurons}

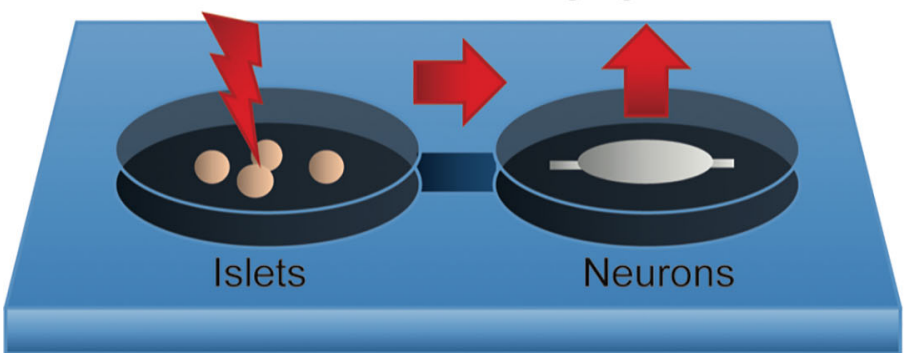

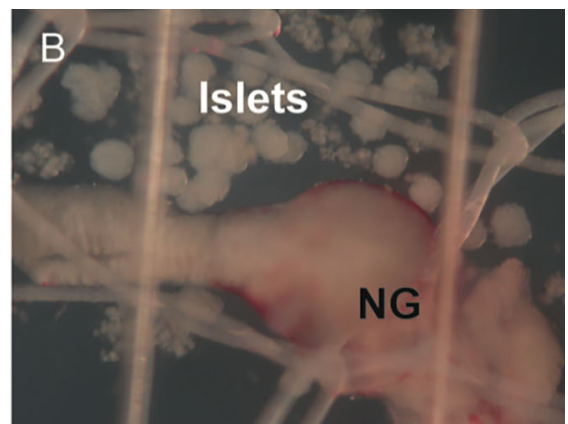

FIGURE 7 | Potential model for recording $\mathrm{Ca}^{2+}$ neuronal activity in response to islet stimulation in vitro. (A) Schematic representation of the proposed experimental setup, where islets are placed upstream of neurons in a perfusion chamber or a microfluidics device. Pharmacological or optogenetic stimulation of islets will induce release of substances that have a potential to act on downstream neurons. (B) Representative photomicrograph of islets placed in close proximity to the nodose ganglion (NG) in an imaging chamber. 
the neuroscience field offers a variety of ready to use tools for neuronal labeling and manipulation (e.g. transgenic mice, genetically encoded reporters, optogenetics). Although the pancreas remains a difficult organ to study, we now can deploy an arsenal of tools that will allow us tackling many longstanding questions in the field of pancreatic innervation.

\section{AUTHOR CONTRIBUTIONS}

MM wrote the original draft of the manuscript. AC reviewed the original draft, edited and approved final version of the

\section{REFERENCES}

1. Pavlov I. Full Collection of Works. USSR, Moscow: Academy of Sciences (1952).

2. Richins CA. The Innervation of the Pancreas. J Comp Neurol (1945) 83:223. doi: 10.1002/cne.900830303

3. Li W, Yu G, Liu Y, Sha L. Intrapancreatic Ganglia and Neural Regulation of Pancreatic Endocrine Secretion. Front Neurosci (2019) 13:21. doi: 10.3389/ fnins.2019.00021

4. Rodriguez-Diaz R, Caicedo A. Neural Control of the Endocrine Pancreas. Best Pract Res Clin Endocrinol Metab (2014) 28:745-56. doi: 10.1016/ j.beem.2014.05.002

5. Love JA, Yi E, Smith TG. Autonomic Pathways Regulating Pancreatic Exocrine Secretion. Auton Neurosci (2007) 133:19-34. doi: 10.1016/ j.autneu.2006.10.001

6. Brunicardi FC, Shavelle DM, Andersen DK. Neural Regulation of the Endocrine Pancreas. Int J Pancreatol (1995) 18:177-95. doi: 10.1007/ BF02784941

7. Havel PJ, Taborsky GJJr.. The Contribution of the Autonomic Nervous System to Changes of Glucagon and Insulin Secretion During Hypoglycemic Stress. Endocr Rev (1989) 10:332-50. doi: 10.1210/edrv-10-3-332

8. Kirchgessner AL, Pintar JE. Guinea Pig Pancreatic Ganglia: Projections, Transmitter Content, and the Type-Specific Localization of Monoamine Oxidase. J Comp Neurol (1991) 305:613-31. doi: 10.1002/cne.903050407

9. Tang SC, Baeyens L, Shen CN, Peng SJ, Chien HJ, Scheel DW, et al. Human Pancreatic Neuro-Insular Network in Health and Fatty Infiltration. Diabetologia (2018) 61:168-81. doi: 10.1007/s00125-017-4409-x

10. Persson-Sjogren S, Zashihin A, Forsgren S. Nerve Cells Associated With the Endocrine Pancreas in Young Mice: An Ultrastructural Analysis of the Neuroinsular Complex Type I. Histochem J (2001) 33:373-8. doi: 10.1023/ A:1012439510709

11. Chien HJ, Chiang TC, Peng SJ, Chung MH, Chou YH, Lee CY, et al. Human Pancreatic Afferent and Efferent Nerves: Mapping and 3-D Illustration of Exocrine, Endocrine, and Adipose Innervation. Am J Physiol Gastrointest Liver Physiol (2019) 317:G694-706. doi: 10.1152/ajpgi.00116.2019

12. Berthoud HR, Powley TL. Morphology and Distribution of Efferent Vagal Innervation of Rat Pancreas as Revealed With Anterograde Transport of Dil. Brain Res (1991) 553:336-41. doi: 10.1016/0006-8993(91)90846-N

13. Wang J, Zheng H, Berthoud HR. Functional Vagal Input to Chemically Identified Neurons in Pancreatic Ganglia as Revealed by Fos Expression. Am J Physiol (1999) 277:E958-64. doi: 10.1152/ajpendo.1999.277.5.E958

14. Makhmutova M, Weitz J, Tamayo A, Pereira E, Boulina M, Almaca J, et al. Pancreatic Beta-Cells Communicate With Vagal Neurons. Gastroenterology (2021) 160(3):875-88.e11. doi: 10.1053/j.gastro.2020.10.034

15. Yi E, Smith TG, Baker RC, Love JA. Catecholamines and 5Hydroxytryptamine in Tissues of the Rabbit Exocrine Pancreas. Pancreas (2004) 29:218-24. doi: 10.1097/00006676-200410000-00007

16. Berthoud HR, Patterson LM, Zheng H. Vagal-Enteric Interface: Vagal Activation-Induced Expression of c-Fos and p-CREB in Neurons of the Upper Gastrointestinal Tract and Pancreas. Anat Rec (2001) 262:29-40. doi: 10.1002/1097-0185(20010101)262:1<29::AID-AR1008>3.0.CO;2-B manuscript, and designed the figures. All authors contributed to the article and approved the submitted version.

\section{FUNDING}

This work was supported by the Diabetes Research Institute Foundation and National Institutes of Health grants R56DK084321 (AC), R01DK084321 (AC), R01DK111538 (AC), R01DK113093 (AC), U01DK120456 (AC) R33ES025673 (AC) and R21ES025673 (AC), F31DK112596 (MM), the Leona M. and Harry B. Helmsley Charitable Trust grants G-2018PG-T1D034 and G-1912-03552.

17. Kirchgessner AL, Gershon MD. Innervation of the Pancreas by Neurons in the Gut. J Neurosci (1990) 10:1626-42. doi: 10.1523/JNEUROSCI.10-0501626.1990

18. Sharkey KA, Williams RG, Dockray GJ. Sensory Substance P Innervation of the Stomach and Pancreas. Demonstration of Capsaicin-Sensitive Sensory Neurons in the Rat by Combined Immunohistochemistry and Retrograde Tracing. Gastroenterology (1984) 87:914-21. doi: 10.1016/0016-5085(84)90088-X

19. Rodriguez-Diaz R, Abdulreda MH, Formoso AL, Gans I, Ricordi C, Berggren PO, et al. Innervation Patterns of Autonomic Axons in the Human Endocrine Pancreas. Cell Metab (2011) 14:45-54. doi: 10.1016/j.cmet.2011.05.008

20. van Westerloo DJ, Giebelen IA, Florquin S, Bruno MJ, Larosa GJ, Ulloa L, et al. The Vagus Nerve and Nicotinic Receptors Modulate Experimental Pancreatitis Severity in Mice. Gastroenterology (2006) 130:1822-30. doi: 10.1053/j.gastro.2006.02.022

21. Weitz J, Diaz RR, Almaca J, Makhmutova M, Caicedo A. Anti-Inflammatory Cholinergic Signals Inhibit Islet Resident Macrophage Responses to ATP in Living Pancreatic Tissue Slices. Diabetes (2018) 67:197-OR. doi: 10.2337/ db18-197-OR

22. Reinert RB, Cai Q, Hong JY, Plank JL, Aamodt K, Prasad N, et al. Vascular Endothelial Growth Factor Coordinates Islet Innervation Via Vascular Scaffolding. Development (2014) 141:1480-91. doi: 10.1242/dev.098657

23. Scott MM, Williams KW, Rossi J, Lee CE, Elmquist JK. Leptin Receptor Expression in Hindbrain Glp-1 Neurons Regulates Food Intake and Energy Balance in Mice. J Clin Invest (2011) 121:2413-21. doi: 10.1172/JCI43703

24. Bloom SR, Edwards AV. Pancreatic Endocrine Responses to Stimulation of the Peripheral Ends of the Vagus Nerves in Conscious Calves. J Physiol (1981) 315:31-41. doi: 10.1113/jphysiol.1981.sp013730

25. King BF, Love JA, Szurszewski JH. Intracellular Recordings From Pancreatic Ganglia of the Cat. J Physiol (1989) 419:379-403. doi: 10.1113/ jphysiol.1989.sp017877

26. Kirchgessner AL, Liu MT. Immunohistochemical Localization of Nicotinic Acetylcholine Receptors in the Guinea Pig Bowel and Pancreas. J Comp Neurol (1998) 390:497-514. doi: 10.1002/(SICI)1096-9861(19980126) 390:4<497::AID-CNE4>3.0.CO;2-W

27. Love JA. Electrical Properties and Synaptic Potentials of Rabbit Pancreatic Neurons. Auton Neurosci (2000) 84:68-77. doi: 10.1016/S1566-0702(00)00187-9

28. Nishi S, Seino Y, Ishida H, Seno M, Taminato T, Sakurai H, et al. Vagal Regulation of Insulin, Glucagon, and Somatostatin Secretion In Vitro in the Rat. J Clin Invest (1987) 79:1191-6. doi: 10.1172/JCI112936

29. Sha L, Love JA, Ma RC, Szurszewski JH. Cholinergic Transmission in Pancreatic Ganglia of the Cat. Pancreas (1997) 14:83-93. doi: 10.1097/ 00006676-199701000-00013

30. Stagner JI, Samols E. Modulation of Insulin Secretion by Pancreatic Ganglionic Nicotinic Receptors. Diabetes (1986) 35:849-54. doi: 10.2337/ diab.35.8.849

31. Kirchgessner AL, Gershon MD. Presynaptic Inhibition by Serotonin of NerveMediated Secretion of Pancreatic Amylase. Am J Physiol (1995) 268:G339-45. doi: 10.1152/ajpgi.1995.268.2.G339

32. Ma RC, Szurszewski JH. 5-Hydroxytryptamine Depolarizes Neurons of Cat Pancreatic Ganglia. J Auton Nerv Syst (1996) 57:78-86. doi: 10.1016/01651838(95)00100-X 
33. Sha L, Miller SM, Szurszewski JH. Nitric Oxide is a Neuromodulator in Cat Pancreatic Ganglia: Histochemical and Electrophysiological Study. Neurosci Lett (1995) 192:77-80. doi: 10.1016/0304-3940(95)11614-3

34. Yi E, Love JA. Alpha-Adrenergic Modulation of Synaptic Transmission in Rabbit Pancreatic Ganglia. Auton Neurosci (2005) 122:45-57. doi: 10.1016/ j.autneu.2005.07.008

35. Yi E, Love JA. Short-Term Synaptic Plasticity in Rabbit Pancreatic Ganglia. Auton Neurosci (2005) 119:36-47. doi: 10.1016/j.autneu.2005.03.001

36. Buijs RM, Chun SJ, Niijima A, Romijn HJ, Nagai K. Parasympathetic and Sympathetic Control of the Pancreas: A Role for the Suprachiasmatic Nucleus and Other Hypothalamic Centers That are Involved in the Regulation of Food Intake. J Comp Neurol (2001) 431:405-23. doi: 10.1002/1096-9861(20010319) 431:4<405::AID-CNE1079>3.0.CO;2-D

37. Daniel PM, Henderson JR. The Effect of Vagal Stimulation on Plasma Insulin and Glucose Levels in the Baboon. J Physiol (1967) 192:317-27. doi: 10.1113/ jphysiol.1967.sp008302

38. Frohman LA, Ezdinli EZ, Javid R. Effect of Vagotomy and Vagal Stimulation on Insulin Secretion. Diabetes (1967) 16:443-8. doi: 10.2337/ diab.16.7.443

39. Meyers EE, Kronemberger A, Lira V, Rahmouni K, Stauss HM. Contrasting Effects of Afferent and Efferent Vagal Nerve Stimulation on Insulin Secretion and Blood Glucose Regulation. Physiol Rep (2016) 4(4):e12718. doi: 10.14814/ phy2.12718

40. Niebergall-Roth E, Singer MV. Central and Peripheral Neural Control of Pancreatic Exocrine Secretion. J Physiol Pharmacol (2001) 52:523-38.

41. Rohner-Jeanrenaud F, Bobbioni E, Ionescu E, Sauter JF, Jeanrenaud B. Central Nervous System Regulation of Insulin Secretion. Adv Metab Disord (1983) 10:193-220. doi: 10.1016/B978-0-12-027310-2.50012-8

42. Streefland C, Maes FW, Bohus B. Autonomic Brainstem Projections to the Pancreas: A Retrograde Transneuronal Viral Tracing Study in the Rat. J Auton Nerv Syst (1998) 74:71-81. doi: 10.1016/S0165-1838(98)00047-2

43. Quinson N, Robbins HL, Clark MJ, Furness JB. Locations and Innervation of Cell Bodies of Sympathetic Neurons Projecting to the Gastrointestinal Tract in the Rat. Arch Histol Cytol (2001) 64:281-94. doi: 10.1679/aohc. 64.281

44. Dunning BE, Taborsky GJ Jr. Neural Control of Islet Function by Norepinephrine and Sympathetic Neuropeptides. Adv Exp Med Biol (1991) 291:107-27. doi: 10.1007/978-1-4684-5931-9_10

45. Dunning BE, Ahren B, Veith RC, Taborsky GJJr. Nonadrenergic Sympathetic Neural Influences on Basal Pancreatic Hormone Secretion. Am J Physiol (1988) 255:E785-92. doi: 10.1152/ajpendo.1988.255.6.E785

46. Christoffersson G, Ratliff SS, von Herrath MG. Interference With Pancreatic Sympathetic Signaling Halts the Onset of Diabetes in Mice. Sci Adv (2020) 6 (35):eabb2878. doi: 10.1126/sciadv.abb2878

47. Guyot M, Simon T, Ceppo F, Panzolini C, Guyon A, Lavergne J, et al. Pancreatic Nerve Electrostimulation Inhibits Recent-Onset Autoimmune Diabetes. Nat Biotechnol (2019) 37:1446-51. doi: 10.1038/s41587-019-0295-8

48. Mundinger TO, Mei Q, Foulis AK, Fligner CL, Hull RL, Taborsky GJ Jr. Human Type 1 Diabetes is Characterized by an Early, Marked, Sustained, and Islet-Selective Loss of Sympathetic Nerves. Diabetes (2016) 65:2322-30. doi: $10.2337 / \mathrm{db} 16-0284$

49. Bou Karam J, Cai W, Mohamed R, Huang T, Meng L, Homan EP, et al. TRPV1 Neurons Regulate Beta-Cell Function in a Sex-Dependent Manner. Mol Metab (2018) 18:60-7. doi: 10.1016/j.molmet.2018.10.002

50. Fasanella KE, Christianson JA, Chanthaphavong RS, Davis BM. Distribution and Neurochemical Identification of Pancreatic Afferents in the Mouse. J Comp Neurol (2008) 509:42-52. doi: 10.1002/cne.21736

51. Neuhuber WL. Vagal Afferent Fibers Almost Exclusively Innervate Islets in the Rat Pancreas as Demonstrated by Anterograde Tracing. J Auton Nerv Syst (1989) 29:13-8. doi: 10.1016/0165-1838(89)90015-5

52. Hameed M, Hameed H, Erdek M. Pain Management in Pancreatic Cancer. Cancers (Basel) (2010) 3:43-60. doi: 10.3390/cancers3010043

53. Pasricha PJ. Unraveling the Mystery of Pain in Chronic Pancreatitis. Nat Rev Gastroenterol Hepatol (2012) 9:140-51. doi: 10.1038/nrgastro.2011.274

54. Schloithe AC, Sutherland K, Woods CM, Blackshaw LA, Davison JS, Toouli J, et al. A Novel Preparation to Study Rat Pancreatic Spinal and Vagal Mechanosensitive Afferents In Vitro. Neurogastroenterol Motil (2008) 20:1060-9. doi: 10.1111/j.1365-2982.2008.01141.x
55. Sha L, Ou LL, Miller SM, Ma R, Szurszewski JH. Cat Pancreatic Neurons: Morphology, Electrophysiological Properties, and Responses to 5-HT. Pancreas (1996) 13:111-24. doi: 10.1097/00006676-199608000-00001

56. Kirchgessner AL, Liu MT, Raymond JR, Gershon MD. Identification of Cells That Express 5-hydroxytryptamine1A Receptors in the Nervous Systems of the Bowel and Pancreas. J Comp Neurol (1996) 364:439-55. doi: 10.1002/ (SICI) 1096-9861(19960115)364:3<439::AID-CNE5>3.0.CO;2-5

57. Kirchgessner AL, Liu MT, Gershon MD. In Situ Identification and Visualization of Neurons That Mediate Enteric and Enteropancreatic Reflexes. J Comp Neurol (1996) 371:270-86. doi: 10.1002/(SICI)1096-9861 (19960722)371:2<270::AID-CNE7>3.0.CO;2-\#

58. Kirchgessner AL, Gershon MD. Innervation and Regulation of the Pancreas by Neurons in the Gut. Z Gastroenterol Verh (1991) 26:230-3. doi: 10.1523/ JNEUROSCI.10-05-01626.1990

59. Kirchgessner AL, Adlersberg MA, Gershon MD. Colonization of the Developing Pancreas by Neural Precursors From the Bowel. Dev Dyn (1992) 194:142-54. doi: 10.1002/aja.1001940207

60. Tharakan T, Kirchgessner AL, Baxi LV, Gershon MD. Appearance of Neuropeptides and NADPH-diaphorase During Development of the Enteropancreatic Innervation. Brain Res Dev Brain Res (1995) 84:26-38. doi: 10.1016/0165-3806(94)00142-M

61. Heidenhain R. Beiträge Zur Kenntniss Des Pancreas. Archiv Für Die Gesamte Physiol Des Menschen Und Der Tiere (1875) 10:557-632. doi: 10.1007/ BF01639951

62. Alm P, Cegrell L, Ehinger B, Falck B. Remarkable Adrenergic Nerves in the Exocrine Pancreas]. Z Zellforsch Mikrosk Anat (1967) 83:178-86. doi: 10.1007/BF00362399

63. Furlan A, La Manno G, Lubke M, Haring M, Abdo H, Hochgerner H, et al. Visceral Motor Neuron Diversity Delineates a Cellular Basis for Nipple- and Pilo-Erection Muscle Control. Nat Neurosci (2016) 19:1331-40. doi: 10.1038/ nn. 4376

64. Kupari J, Haring M, Agirre E, Castelo-Branco G, Ernfors P. An Atlas of Vagal Sensory Neurons and Their Molecular Specialization. Cell Rep (2019) 27:2508-2523 e4. doi: 10.1016/j.celrep.2019.04.096

65. Glynn MW, McAllister AK. Immunocytochemistry and Quantification of Protein Colocalization in Cultured Neurons. Nat Protoc (2006) 1:1287-96. doi: $10.1038 /$ nprot.2006.220

66. Daigle TL, Madisen L, Hage TA, Valley MT, Knoblich U, Larsen RS, et al. A Suite of Transgenic Driver and Reporter Mouse Lines With Enhanced BrainCell-Type Targeting and Functionality. Cell (2018) 174:465-480 e22. doi: 10.1016/j.cell.2018.06.035

67. Udit S, Gautron L. Molecular Anatomy of the Gut-Brain Axis Revealed With Transgenic Technologies: Implications in Metabolic Research. Front Neurosci (2013) 7:134. doi: 10.3389/fnins.2013.00134

68. Davidson BL, Breakefield XO. Viral Vectors for Gene Delivery to the Nervous System. Nat Rev Neurosci (2003) 4:353-64. doi: 10.1038/nrn1104

69. Rosario W, Singh I, Wautlet A, Patterson C, Flak J, Becker TC, et al. The Brain-to-Pancreatic Islet Neuronal Map Reveals Differential Glucose Regulation From Distinct Hypothalamic Regions. Diabetes (2016) 65:271123. doi: $10.2337 / \mathrm{db} 15-0629$

70. Xiao X, Guo P, Prasadan K, Shiota C, Peirish L, Fischbach S, et al. Pancreatic Cell Tracing, Lineage Tagging and Targeted Genetic Manipulations in Multiple Cell Types Using Pancreatic Ductal Infusion of Adeno-Associated Viral Vectors and/or Cell-Tagging Dyes. Nat Protoc (2014) 9:2719-24. doi: 10.1038/nprot.2014.183

71. Alvarsson A, Jimenez-Gonzalez M, Li R, Rosselot C, Tzavaras N, Wu Z, et al. A 3D Atlas of the Dynamic and Regional Variation of Pancreatic Innervation in Diabetes. Sci $A d v$ (2020) 6(41):eaaz9124. doi: 10.1126/sciadv.aaz9124

72. Hara M, Dizon RF, Glick BS, Lee CS, Kaestner KH, Piston DW, et al. Imaging Pancreatic Beta-Cells in the Intact Pancreas. Am J Physiol Endocrinol Metab (2006) 290:E1041-7. doi: 10.1152/ajpendo.00365.2005

73. Hsueh B, Burns VM, Pauerstein P, Holzem K, Ye L, Engberg K, et al. Pathways to Clinical CLARITY: Volumetric Analysis of Irregular, Soft, and Heterogeneous Tissues in Development and Disease. Sci Rep (2017) 7:5899. doi: 10.1038/s41598-017-05614-4

74. Tang SC, Shen CN, Lin PY, Peng SJ, Chien HJ, Chou YH, et al. Pancreatic Neuro-Insular Network in Young Mice Revealed by 3D Panoramic Histology. Diabetologia (2018) 61:158-67. doi: 10.1007/s00125-017-4408-y 
75. Ahl D, Eriksson O, Sedin J, Seignez C, Schwan E, Kreuger J, et al. Turning Up the Heat: Local Temperature Control During In Vivo Imaging of Immune Cells. Front Immunol (2019) 10:2036. doi: 10.3389/fimmu.2019.02036

76. Frikke-Schmidt H, Arvan P, Seeley RJ, Cras-Meneur C. Improved In Vivo Imaging Method for Individual Islets Across the Mouse Pancreas Reveals a Heterogeneous Insulin Secretion Response to Glucose. Sci Rep (2021) 11:603. doi: 10.1038/s41598-020-79727-8

77. Reissaus CA, Pineros AR, Twigg AN, Orr KS, Conteh AM, Martinez MM, et al. Portable Intravital Microscopy Platform for Studying Beta-Cell Biology In Vivo. Sci Rep (2019) 9:8449. doi: 10.1038/s41598-019-44777-0

78. Almaca J, Weitz J, Rodriguez-Diaz R, Pereira E, Caicedo A. The Pericyte of the Pancreatic Islet Regulates Capillary Diameter and Local Blood Flow. Cell Metab (2018) 27:630-44.e4. doi: 10.1016/j.cmet.2018.02.016

79. Marciniak A, Cohrs CM, Tsata V, Chouinard JA, Selck C, Stertmann J, et al. Using Pancreas Tissue Slices for in Situ Studies of Islet of Langerhans and Acinar Cell Biology. Nat Protoc (2014) 9:2809-22. doi: 10.1038/nprot.2014.195

80. Panzer JK, Hiller H, Cohrs CM, Almaca J, Enos SJ, Beery M, et al. Pancreas Tissue Slices From Organ Donors Enable in Situ Analysis of Type 1 Diabetes Pathogenesis. JCI Insight (2020) 5(8):e134525. doi: 10.1172/jci.insight.134525

81. Weitz JR, Makhmutova M, Almaca J, Stertmann J, Aamodt K, Brissova M, et al. Mouse Pancreatic Islet Macrophages Use Locally Released ATP to Monitor Beta Cell Activity. Diabetologia (2018) 61:182-92. doi: 10.1007/s00125-017-4416-y

82. Speier S, Nyqvist D, Cabrera O, Yu J, Molano RD, Pileggi A, et al. Noninvasive In Vivo Imaging of Pancreatic Islet Cell Biology. Nat Med (2008) 14:574-8. doi: $10.1038 / \mathrm{nm} 1701$

83. Speier S, Nyqvist D, Kohler M, Caicedo A, Leibiger IB, Berggren PO. Noninvasive High-Resolution In Vivo Imaging of Cell Biology in the Anterior Chamber of the Mouse Eye. Nat Protoc (2008) 3:1278-86. doi: 10.1038/ nprot.2008.118

84. Rodriguez-Diaz R, Speier S, Molano RD, Formoso A, Gans I, Abdulreda MH, et al. Noninvasive In Vivo Model Demonstrating the Effects of Autonomic Innervation on Pancreatic Islet Function. Proc Natl Acad Sci USA (2012) 109:21456-61. doi: 10.1073/pnas.1211659110

85. Singer MV, Solomon TE, Wood J, Grossman MI. Latency of Pancreatic Enzyme Response to Intraduodenal Stimulants. Am J Physiol (1980) 238:G239. doi: 10.1152/ajpgi.1980.238.1.G23

86. Rinaman L, Miselis RR. The Organization of Vagal Innervation of Rat Pancreas Using Cholera Toxin-Horseradish Peroxidase Conjugate. J Auton Nerv Syst (1987) 21:109-25. doi: 10.1016/0165-1838(87)90014-2

87. DeNardo LA, Liu CD, Allen WE, Adams EL, Friedmann D, Fu L, et al. Temporal Evolution of Cortical Ensembles Promoting Remote Memory Retrieval. Nat Neurosci (2019) 22:460-9. doi: 10.1038/s41593-018-0318-7

88. Schwenkgrub J, Harrell ER, Bathellier B, Bouvier J. Deep Imaging in the Brainstem Reveals Functional Heterogeneity in V2a Neurons Controlling Locomotion. Sci $A d v$ (2020) 6(49):eabc6309. doi: 10.1126/sciadv.abc6309
89. Stein LM, Lhamo R, Cao A, Workinger J, Tinsley I, Doyle RP, et al. Dorsal Vagal Complex and Hypothalamic Glia Differentially Respond to Leptin and Energy Balance Dysregulation. Transl Psychiatry (2020) 10:90. doi: 10.1038/ s41398-020-0767-0

90. Furuzawa Y, Ohmori Y, Watanabe T. Anatomical Localization of Sympathetic Postganglionic and Sensory Neurons Innervating the Pancreas of the Cat. $J$ Vet Med Sci (1996) 58:243-8. doi: 10.1292/jvms.58.243

91. Jobling P, Gibbins IL. Electrophysiological and Morphological Diversity of Mouse Sympathetic Neurons. J Neurophysiol (1999) 82:2747-64. doi: 10.1152/ jn.1999.82.5.2747

92. Razavi R, Chan Y, Afifiyan FN, Liu XJ, Wan X, Yantha J, et al. TRPV1+ Sensory Neurons Control Beta Cell Stress and Islet Inflammation in Autoimmune Diabetes. Cell (2006) 127:1123-35. doi: 10.1016/j.cell.2006.10.038

93. Riera CE, Huising MO, Follett P, Leblanc M, Halloran J, Van Andel R, et al. TRPV1 Pain Receptors Regulate Longevity and Metabolism by Neuropeptide Signaling. Cell (2014) 157:1023-36. doi: 10.1016/j.cell.2014.03.051

94. Chen C, Zhang J, Sun L, Zhang Y, Gan WB, Tang P, et al. Long-Term Imaging of Dorsal Root Ganglia in Awake Behaving Mice. Nat Commun (2019) 10:3087. doi: 10.1038/s41467-019-11158-0

95. Field HA, Dong PD, Beis D, Stainier DY. Formation of the Digestive System in Zebrafish. II Pancreas Morphogen Dev Biol (2003) 261:197-208. doi: 10.1016/ S0012-1606(03)00308-7

96. Matsuda H. Zebrafish as a Model for Studying Functional Pancreatic Beta Cells Development and Regeneration. Dev Growth Differ (2018) 60:393-9. doi: 10.1111/dgd. 12565

97. Yang YHC, Kawakami K, Stainier DY. A New Mode of Pancreatic Islet Innervation Revealed by Live Imaging in Zebrafish. Elife (2018) 7:e34519. doi: 10.7554/eLife. 34519

98. Bohorquez DV, Shahid RA, Erdmann A, Kreger AM, Wang Y, Calakos N, et al. Neuroepithelial Circuit Formed by Innervation of Sensory Enteroendocrine Cells. J Clin Invest (2015) 125:782-6. doi: 10.1172/JCI78361

99. Borden P, Houtz J, Leach SD, Kuruvilla R. Sympathetic Innervation During Development is Necessary for Pancreatic Islet Architecture and Functional Maturation. Cell Rep (2013) 4:287-301. doi: 10.1016/j.celrep.2013.06.019

Conflict of Interest: The authors declare that the research was conducted in the absence of any commercial or financial relationships that could be construed as a potential conflict of interest.

Copyright (c) 2021 Makhmutova and Caicedo. This is an open-access article distributed under the terms of the Creative Commons Attribution License (CC BY). The use, distribution or reproduction in other forums is permitted, provided the original author(s) and the copyright owner(s) are credited and that the original publication in this journal is cited, in accordance with accepted academic practice. No use, distribution or reproduction is permitted which does not comply with these terms. 